This is an electronic reprint of the original article. This reprint may differ from the original in pagination and typographic detail.

Author(s): Ngwayuh, Elvis Nshom; Croucher, Stephen

Title: $\quad$ Threats and attitudes toward Russian-speaking immigrants: a comparative study between younger and older Finns

Year: $\quad 2014$

Version:

Please cite the original version:

Ngwayuh, E. N., \& Croucher, S. (2014). Threats and attitudes toward Russian-

speaking immigrants: a comparative study between younger and older Finns. Russian Journal of Communication, 6(3), 308-317.

https://doi.org/10.1080/19409419.2014.954599

All material supplied via JYX is protected by copyright and other intellectual property rights, and duplication or sale of all or part of any of the repository collections is not permitted, except that material may be duplicated by you for your research use or educational purposes in electronic or print form. You must obtain permission for any other use. Electronic or print copies may not be offered, whether for sale or otherwise to anyone who is not an authorised user. 
THREATS AND ATTITUDES TOWARD RUSSIAN-SPEAKING IMMIGRANTS: A COMPARATIVE STUDY BETWEEN YOUNGER AND OLDER FINNS

by

Nshom, E. \& Croucher, S. M. (2014)

Russian Journal of Communication, 6, 308-317

Reproduced with kind permission by the publisher. 
Nshom, E. \& Croucher, S. M. (2014). Threats and attitudes toward Russian-speaking immigrants: a comparative study between younger and older Finns. Russian Journal of Communication, 6, 308-317.

\title{
Threats and attitudes toward Russian-speaking immigrants: a comparative study between younger and older Finns
}

\author{
Elvis Nshom and Stephen Michael Croucher \\ Department of language and communication studies \\ University of Jyväskylä, Jyväskylä, Finland \\ (Received 3 February 2014; accepted 17 June 2014)
}

\begin{abstract}
Using integrated threat theory as a theoretical lens to detect negative attitudes toward minority groups, this study compares and contrasts the perceptions and attitudes of older and younger Finns toward Russian-speaking minorities in Finland. A sample of high school students between 16 and 20 years of age represented the younger generation, while individuals over 65 years of age represented the older generation. The total sample was 242 . Results indicated that there is a positive correlation between threat perception and prejudice. Results revealed that both groups have prejudices against Russian speakers and that these prejudices are related to the perception of realistic threat and negative stereotypes. The study also found that the older generation had more feelings of threat and prejudice than the younger generation. Implications and future areas of research are discussed.
\end{abstract}

Keywords: integrated threat theory; immigration; prejudice; Russian immigrants; Finland 


\section{Introduction and background}

Recent analyses reveal that negative, xenophobic, and even racist attitudes are widespread in Europe, and many Europeans have voiced worries concerning minorities due to the perception that minorities are a threat to social peace and welfare (Ervasti, 2004). Ethnic threat perception is said to be a core explanatory factor for widespread anti-immigrant attitudes in Europe (Schneider, 2008; Stephan, Diaz-Looving, \& Duran, 2000). Traditionally speaking, Finland until recently, compared to other European countries such as Italy, Britain, and France has been a homogenous country and highly excluded from massive immigration (Ervasti, 2004; Jasinskaja-Lahti, 2000; Jasinskaja-Lahti \& Liebkind, 2001; Kyntäjä, 1997). However, among the various immigrant groups in Finland, the Russian minority has traditionally been the largest until a recent survey indicated Estonians had slightly overtaken them (Helsingin Sanomat, 2011). However, it is unfortunate that Russian minorities in Finland feel alienated psychologically and emotionally more than other minority groups in Finland and have witnessed or experienced discrimination in different forms such as racial abuse and assaults (Jasinskaja-Lahti \& Liebkind, 2001). This discrimination is predominantly motivated by historical underpinnings between Finland and Russia and on the one side, by the ineffective and inadequate policies to manage immigration in Finland. According to Mannila and Reuter (2009), other studies on Russian immigrants in Finland have mostly focused on psychological adaption and perceived discrimination (JasinskajaLahti et al., 2006; Liebkind et al., 2004). However, few studies have focused particularly on Russianspeaking minorities.

Therefore, this study examines Finnish attitudes toward Russian-speaking immigrants in Finland. Specifically, this study is interested in two aspects of the relationship between Finns and Russian-speaking immigrants. First, this study focuses on the perception of older and younger Finns toward Russian-speaking immigrants in Finland. Ford (2012) argued that younger Europeans are generally more tolerant of immigrants than older Europeans. As many Finns have traditionally had a negative perception of Russian immigrants, it is advantageous to explore the generational divide in attitudes toward Russian-speaking immigrants in Finland, who are still one of the largest immigrant groups in Finland. Second, this study uses Stephan and Stephan's $(1993,1996)$ integrated threat theo- 
ry (ITT) to examine the perceptions of threat Finns have toward Russian-speaking immigrants in Finland. ITT provides a useful framework for understanding how a majority perceives threat from a minority group.

\section{Finnish and Russian relations}

Russians have visibly and increasingly been participants in the history of immigration in Finland. The genesis can be traced to the eighteenth century with the immigration of about 40,000 Russian soldiers and 600 civilian workers and businessmen. The independence of Finland led to the return from Finland to Russia of so many of the aforementioned soldiers and the establishment of some of those businessmen in Finland. There have been three major Russian migratory waves to Finland before WorldWar II. These are those categories of immigrants considered "Old Russians" and they have approximately 3000 to 5000 of their descendants residing in Finland (Niemi, 2007).

Moreover, after the collapse of the Soviet Union, many Russians moved to Finland as guest workers and worked for low-paying jobs. Nevertheless, the peak of Russian immigration in Finland in the twentieth century dates back to the early 1990s with the return of Ingrian Finns and many other people with Finnish ancestry from Russia and other parts of the former Soviet Union. After 1991, with the coming of about 5000 citizens from the former Soviet Union, the total number of people immigrating to Finland from the former Soviet Union and Russia has been about 2000 each year and about half were returnees. These individuals returned for family ties, marriage, and other factors accounting for why Russians get a resident permit to Finland (Jasinskaja-Lahti \& Liebkind, 1998; Niemi, 2007). For example, mixed marriages between Finnish men and Russian women are a common phenomenon in the Eastern part of Finland. In the eastern part of Finland, about 2\% of the population is immigrants. Among the various immigrant groups, the Russians are the most popular (Joensuu Kaupunki, 2010). Understanding the history of Finland vis-à-vis its involvement with Russia is paramount to our understanding of the perception and attitudinal climate of Finland toward its Eastern neighbors. The origin of anti-Russian attitudes is deeply planted and connected to the common history between Finland and Russia. According to Karemaa (2004), the genesis of negative stereotypical per- 
ceptions of Russians in Europe as devious, bestial, violent, lecherous, and drunken barbarians dates back to the sixteenth century. Many of these stereotypes according to her are still alive and active in society. These stereotypes have gained Russians the reputation of being the most common representation of "otherness" in European thinking. Similarly, Finland was also influenced by these negative stereotypes about Russians, but these stereotypes reportedly appear not to have been widespread. Finland was under Russian domination from 1808 until 1917 when Finland announced its independence. Both countries fought major wars including the Winter War of 1939-1940 and its continuation in 1941-1944. Branding Russians as archenemies and as the barbaric "other" was therefore inevitable. In the last two decades of the nineteenth century, anti-Russian attitudes in Finland were reignited as the younger generation criticized their elders after hearing the stories of their struggles from the hands of their oppressors (Russians), for having dealt with the Russians in a laissez-faire manner, and not even being able to hate them. Consequently, Russians living in Finland have traditionally been victims of ethnic prejudice and discrimination (Jaakkola, 2000; Protassova, 2008), and this was also noted internationally by the European Commission against Racism and Intolerance (ECRI, 2007).

\section{Integrated threat theory}

Threat perceptions and fear largely contribute to negative attitudes toward minorities and immigrants (González, Verkuyten, Weesie, \& Poppe, 2008; Stephan et al., 2000). The ITT of prejudice by Stephan and Stephan $(1993,1996)$ provides a useful framework for understanding prejudice and discrimination among out-groups (González et al., 2008; Khan \& Wiseman, 2007; Scheibner \& Morrison, 2009; Schweitzer, Perkoulidis, Krome, \& Ludlow, 2005; Stephan et al., 2000; Stephan \& Stephan, 1996; Stephan Ybarra, Martinez, Schwarzwald, \& Turk-Kaspa, 1998).

This theory suggests that there are four major threat perceptions that can lead to negative attitudes toward an out-group: realistic threats, symbolic threats, intergroup anxiety, and negative stereotypes (Croucher, 2013; Croucher et al., 2013; Stephan \& Stephan, 1993). Realistic threats are those posed to the in-group by the very existence of the out-group. These are threats related to the economic and 
political power, and physical or material well-being of the in-group or its members. González et al. (2008) stated:

The core issue here is (perceived) competition over scarce resources, such as houses and jobs, and the perception that these resources are threatened by outsiders. The desire to protect the in-group's interests is considered the underlying motivation responsible for negative attitudes and discriminatory behavior. (p. 669)

In Finland, the political party the True Finns has consistently linked rising unemployment with the presence of immigrants, such as Estonian and Russian immigrants (Finnish National Broadcasting Company, 2011).

Symbolic threats are threats that emerge as a result of differences in morals, values, standards, beliefs, or attitudes between the in-group and the out-group. These are seen as threats to the way of life of the in-group. Usually out-groups that adhere to different views often threaten the ingroup and as a consequence are disliked by the in-group (Stephan et al., 2000). In the context of contemporary Europe, immigrants are in most cases perceived as different because of their religious and cultural values. These values and beliefs are perceived as threats to the dominant population, which in most cases is believed to be correct (McLaren, 2003; Stephan et al., 1998, as quoted in Curseu, Stoop, \& Schalk, 2007).

Intergroup anxiety usually happens in the process of in-group interaction with out-group members. This anxiety or feeling arises because of the fear of embarrassment, ridicule, rejection, exploitation, etc. (Stephan et al., 2000) or when the out-group and the in-group both have a history of antagonism (for example the case of Finland and Russia) or because of little or no prior personal contact.

On the other hand, negative stereotypes are implied threats to the in-group. This is because in the course of interaction with out-group members, in-group members fear negative consequences will befall them because they have negative expectations of the out-group (Stephan et al., 1998). The common history between Finland and Russia characterized by conflict has traditionally gained Rus- 
sians the reputation of archenemies in Finland, and according to Karemaa (2004), this negative stereotypical perception has been transferred from one generation to another and is present in Finnish society today. According to Lehtonen (2005), stereotypes can be transported through different ways of communication such as everyday talk, cultural jokes, phrases and conceits, the wording of news items in newspapers, cartoons, films, and TV ads, just to name a few. Communication can contain transparent or embedded cultural stereotypes. Negative stereotypes and prejudice are related in that they feed each other. Negative stereotypes have been found to be a contributing factor of prejudice and negative attitudes toward out-groups (Ringo, 2005; Stephan et al., 2000).

Studies utilizing ITT in order to understand generational differences in attitudes toward an immigrant group are rare. According to Ford (2012), there are four factors that largely explain the generational differences in European attitudes toward immigrants: education level; immigrant heritage; preferences for cultural, religious, and linguistic diversity; and social contact with immigrants. He explained that younger Europeans, particularly in Western European countries with a long history of immigration, exhibit high levels of the aforementioned factors, for whom attitudes toward immigrants may tend to be more tolerant or liberal. A generation can be defined "as age cohort that shares unique formative year's experiences and teachings... and thus develop unique core values and attitudes that are different from other generations (Underwood, 2007: 43)" (Delcampo, Haggerty, \& Haney, 2011, p. 5). Similarly, he also observed that the core values and identity orientations of individuals are greatly influenced by the conditions and circumstances of the times in which they grow up.

\section{Research question and hypothesis}

Based on the literature showing there is a history of tension between Finns and Russians-speaking immigrants (Jaakkola, 2000; Protassova, 2008), we believe that ITT can best explain the current relationship between these two groups. As each kind of threat manifests itself between these two groups, we would like to explore the extent to which the different kinds of threat are manifested among Finns toward Russian-speaking immigrants. Thus the following research question is posed: 
RQ: To what extent are the different kinds of threat manifested among Finns from Russianspeaking immigrants?

Furthermore, Ford (2012) demonstrated that generational differences affect perception and acceptance of immigrant groups. Specifically, younger individuals are more likely to perceive lower levels of threats, while older individuals are more likely to perceive higher levels of threat from immigrants. Therefore, we pose the following hypothesis to explore the effect of age on threat:

H: Younger individuals perceive lower levels of threat from Russian-speaking immigrants than older individuals toward Russian-speaking immigrants.

\section{Method}

\section{Participants and procedures}

A total of 242 people in Eastern Finland participated in the study. All of the participants were native Finns, and not Russian-speaking immigrants. Only individuals who were native-Finnish speakers were permitted to complete the survey. The principal investigator asked participants their native language prior to beginning the survey. Of the sample, $152(62.8 \%)$ were high school students between the ages of 16 and 19 years, while $90(37.2 \%)$ were 65 years of age or older. There were a total of 87 (35.9\%) men and $155(64.1 \%)$ women in the sample. Data were collected through questionnaires after appropriate institutional ethics approval. A visit was organized to participating schools and organizations. Participants were explained the purpose of the study and were handed the questionnaire. It took 10-15 minutes to complete the questionnaire.

\section{Measures}

All surveys included demographic questions (gender and age) and the following modified measures: a measure of symbolic threat (González et al., 2008), a measure of realistic threat (González et al., 2008), and a measure of negative stereotypes. The survey was originally prepared in English and then translated/back-translated into Finnish by native speakers of Finnish-English. See Table 1 for the means, standard deviations, correlations, alphas, and kappas for the study variables. 
Realistic threat: To assess realistic threat, the participants were given four statements that measured Finnish perception of Russian-speaking immigrants' effects on the Finnish economy. Studies of integrated threat historically ask about the economy, as economic issues have been found to be one of the most, if not the most, pertinent fear for most individuals (González et al., 2008). These items are based on the work of González et al. (2008). A sample statement is: "The scarcity of jobs in Finland is due to Russian-speaking immigrants." Responses ranged from (1) strongly disagree to (5) strongly agree. Higher scores indicate higher perception of realistic threat. Scales like this have shown high reliability, from .80 to .92 (Croucher, 2013; Croucher et al., 2013; González et al., 2008). A factor analysis on the Finnish translation confirmed all four items should be retained as one factor: KaiserMeyer-Olkin $(\mathrm{KMO})=.77$, and Bartlett's test of Sphericity $\chi 2=268.99, p<.001$.

Symbolic threat: Three items were used to measure symbolic threat (González et al., 2008). A sample item includes "Russian-speaking immigrants have a negative effect on Finnish culture". Responses ranged from (1) strongly disagree to (5) strongly agree. Higher scores indicate higher perception of symbolic threat. Scales such as this have shown high reliability, ranging from .89 to .94 (Croucher, 2013; Croucher et al., 2013; González et al., 2008). A factor analysis of the Finnish translation confirmed that all the three items should be retained as one factor: $\mathrm{KMO}=.71$, and Bartlett's test of Sphericity $\chi^{2}=266.89, p<.001$.

Stereotypes: Individuals were asked the extent to which eight traits describe Russian-speaking immigrants. Four of these traits come from González et al. (2008): violent, dishonest, friendly, and arrogant, and the remaining four traits: respectful, lazy, reliable, and materialistic were designed specifically for this study. Stereotypes are viewed as "generalizations that are assumed to be common among the members of a given in-group and which concern the members of a given collective,... who are assumed to share the same attitudes, personality traits and behavioral predispositions" (Lehtonen, 2005, p. 67). Therefore, we slightly modified the original items measuring stereotypes by González et al. (2008) by adding common stereotypical perceptions of Russian immigrants in the Eastern part of Finland. Responses ranged from (1) no, absolutely not to (5) yes, certainly. The first factor analysis revealed three items with eigenvalues below .40 , thus these items were dropped from the analysis. 
The remaining five items (reverse-coded friendly, violent, dishonest, lazy, and arrogant) were analyzed and a one-factor structure was achieved: $\mathrm{KMO}=.78$, and Bartlett's test of Sphericity $\chi 2=$ 202.90, $p<.001$.

\section{Table 1}

Means, standard deviations, correlations, alphas, and kappas for study variables

Variable

$M \quad S D$

$\kappa$

(1) (2) (3)

(1) Stereotypes $a b$

$\begin{array}{lllll}2.59 & .64 & .71 & .72 & -\end{array}$

(2) Realistic threat ${ }_{a c}$

$\begin{array}{lllll}2.91 & .78 & .78 & .75 & .56 * *\end{array}$

(3) Symbolic threat $\mathrm{bc}$

$\begin{array}{lllll}2.28 & .91 & .82 & .74 & .54 * * .64 * *\end{array}$

Note: subscripts indicate significant mean differences between variables, $* p<.001$.

\section{Results}

To answer the research question, a repeated measures analysis of variance (ANOVA) was conducted. The analysis revealed a significant difference among the different kinds of threat for Finns toward Russian speaking immigrants: $F(1.96,467.06)=89.16, p<.001$. Tukey's multiple comparison procedure was used to find the kind of threat Finns have the most toward Russian-speaking immigrants. Overall, Finns, significantly perceive more realistic threats $(M=2.91)$ from Russian-speaking immigrants than any other kind of threat. See Table 1 for means of each threat.

To test the hypothesis independent samples $t$-tests were conducted. The results of the $t$-tests reveal the following. First, older individuals perceive higher levels of realistic threat $\left(M_{O}=3.01 ; S D_{O}=\right.$ $.87)$ than younger individuals $\left(M_{Y}=2.75 ; S D_{Y}=.70\right)$ from Russian-speaking immigrants, $t(239)=$ $3.18, p<.01$. Second, older individuals perceive higher levels of symbolic threat $\left(M_{O}=2.54 ; S D_{O}=\right.$ $1.00)$ than younger individuals $\left(M_{Y}=2.03 ; S D_{Y}=.80\right)$ from Russian-speaking immigrants, $t(153.38)$ $=-4.11, p<.001$. Third, there is no statistical difference between older individuals stereotyping $\left(M_{O}=\right.$ 
$\left.2.61 ; S D_{O}=.61\right)$ and younger individuals $\left(M_{Y}=2.57 ; S D_{Y}=.65\right)$ stereotyping of Russian-speaking immigrants, $t(192.00)=-.57, p=.57$

\section{Discussion}

This study had two main aims: to understand the extent to which Finns perceive different kinds of threat from Russian-speaking immigrants and to understand the generational divide in threat perception among Finns from Russian-speaking immigrants.

Results indicated that Finns generally perceive Russian speakers more as a realistic threat compared to other threats. This situation may arise due to competition over scarce resources such as jobs, housing, welfare services, or political power, just to name a few. Jaakkola (2000) also showed that Finnish attitudes toward immigrants became sterner during the downturn of the economic depression. This study also supports other studies that utilized ITT to successfully detect threats faced by the majority from the minority and in this case Finns from Russian speakers (González et al., 2008; Khan \& Wiseman, 2007; Scheibner \& Morrison, 2009; Schweitzer et al., 2005; Stephan, et al., 1998, 2000; Stephan \& Stephan, 1996). This study sheds more light on the antagonism that has traditionally existed between these two groups.

Moreover, as hypothesized but not yet empirically measured, it was clear from our study that older Finns perceive Russian speakers as a realistic and symbolic threat more than younger Finns do. This could be an indication that the perception and attitudinal climate toward Russian-speaking immigrants in Eastern Finland are changing and that a generational divide in threat perception does exist, except for negative stereotypes as observed in this study. The exception of negative stereotypes is alarming because this implies younger Finns could hold as many stereotypes of Russian speakers as older Finns. According to Kangas (2011) and Karemaa (2004), Finns have traditionally had stereotypes about Russians and these stereotypes were transferred from one generation to another as parents recounted to their children the struggles they went through in the fight for freedom from the hands of the oppressors (Russians) during the war years. She argued that these negative perceptions of Russians are still alive in the Finnish society. This could be a possible explanation as to why there is no 
significant difference between older and younger Finns in the perception of negative stereotypes toward Russian speakers. It can be argued that negative stereotypical perceptions of Russian immigrants are related to Finnish collective identity. According to Lehtonen (2005), an identification as a part of the collective or in-group could be a commitment to share in not only the in-group's generalized and simplified perception of self "us" but also the out-group's "others" (Russian immigrants). And even though stereotypes are not necessarily negative, they tend to be denigrating when applied to members of a group. In most cases, this forms the basis for intergroup prejudice and may hinder communication, intercultural exchange/dialog, and relationships (Ringo, 2005).

\section{Implications and future research}

While age has been studied in relation to attitudes toward immigrants, studies have not empirically explored age as a factor in attitudes toward immigrants, particularly prejudice/threat.

Ford (2012) did discuss such differences, but this is the only such hypothesis. The current study shows older Finns are more threatened by Russian immigrants than younger Finns. Thus, the first contribution of this study is that it adds to integrated threat research by empirically showing the significance of age as a predictive factor of threat.

Related to age, the second contribution of this study is the study's sample diversity. From a methodological perspective few studies in communication or on immigration have sampled high school students or individuals over 65 years of age. Thus, the current study's sampling represents diverse perspectives that are underrepresented.

Third, this research continues a growing trend of studies that explore the perceptions of the dominant culture, and not the perceptions of the immigrant. Typically in studies of immigration and cultural adaptation studies focus on the experience of the immigrant. While such studies have provided a wealth of information about the immigration experience, such studies have not tackled the pivotal question of host acceptance (Croucher, 2013; Croucher et al., 2013). A host culture is less likely to accept an immigrant group if the host feels threatened by the immigrant group (Croucher, 2013). In the case of the current study, the results show that the main fear Finns have from Russian immigrants 
are realistic threats, such as economic threats. Such threats must be addressed to facilitate cultural adaptation, as it is impossible for immigrants to culturally adapt if they are not welcomed, or if they are feared by the dominant culture (Croucher, 2013; Croucher et al., 2013; Kim, 1988).

We see two areas of future research stemming from this study: the need to explore the effect of threat on intercultural exchange/dialog, and the need for qualitative research on threat. The Council of Europe (2008) defined intercultural dialog as a:

process that comprises an open and respectful exchange or interaction between individuals, groups and organizations with different cultural backgrounds or world views. Among its aims are: to develop a deeper understanding of diverse perspectives and practices; to increase participation and the freedom and ability to make choices; to foster equality; and to enhance creative processes. (p. 10).

We see the study of integrated threat and prejudice as integral to understanding intercultural dialog, as such research is essential to understand the environment in which dialog takes place to be able to foster open and productive exchange (dialog). Numerous political, economic, linguistic, and sociocultural variables can influence the success of intercultural diaolgs (in whatever form the dialog may come) (Carbaugh, Boromisza-Habashi, \& Ge, 2006; Deetz \& Simpson, 2004; Ganesh \& Holmes, 2011; Näss, 2010). We propose that intercultural researchers interested in dialog research negative attitudes between groups (prejudice, stereotypes, threat, etc.) as potential deterrents of effective intercultural dialog.

Moreover, we recommend that future research should focus on utilizing more qualitative or mixed-method approaches to understand the nature of antagonism in intergroup relations. So far the majority of studies looking at threat have used quantitative methods. Through in-depth interviews, we could have access to more profound insight as to how individuals feel, how they perceive immigrant minorities, and other extenuating factors. This kind of research could be done not only for members of the in-group but also for the out-group. Understanding whether the out-group perceives itself as 
threatening to members of the host society and how it affects the nature of their interaction and relationship has not been given considerable attention as of yet.

This study has two limitations: sampling and the impossibility of knowing its effects on the participants. True random sampling is virtually impossible in intercultural and/or cross-cultural research; thus, this study did use a purposive convenience sample. The majority of the participants came from middle- to upper-middle-class families, and thus it is logical to assume such neighborhoods. Therefore, generalizations to the larger Finnish population should be done with caution, as Finland is an economically diverse nation. As the paper focused on Russian immigrants to Finland, the participants for the study were taken from Eastern Finland. This region of Finland borders Russia and has an economic, political, and cultural interest in Russian immigration. Future research should strive for more sample diversity. The second potential limitation of this study is that it is impossible to know if taking this survey could have brought forth prejudices in the younger participants. Even though a debriefing took place after surveys were completed, in which participants were asked to share their thoughts about the survey, such a debriefing may bring forth more prejudicial/stereotypical thoughts. We argue that when studying sensitive issues with any population, one must be diligent to debrief the participants and be sure they have done no harm. We believe we have done our best to this end.

In summary, the results of this study provide support that Finns perceive Russian immigrants as more of a realistic threat than any other kind of threat, and that older Finns are more threated by Russian immigrants than are younger Finns. Further research should continue to explore integrated threat in diverse cultural settings to better understand the intricate relationship between immigrants, dominant group members, and the cultures in which they live. 


\section{References}

Carbaugh, D., Boromisza-Habashi, D., \& Ge. X. (2006). Dialogue in a cross-cultural perspec tive. In N. Alto \& E. Reuter (Eds.), Aspects of intercultural dialogue (pp. 27-46). Koln: SAXAVerlag. Council of Europe. (2008). White paper on intercultural dialogue: "Living together as equals in dignity." Retrieved from www.coe/int/t/dg4/intercultural/source/white\%20paper_final_revised_en.pdf Croucher, S. M. (2013). Integrated threat theory and acceptance of immigrant assimilation: An analysis of Muslim immigration in Western Europe. Communication Mono graphs, 80, 46-62.

Croucher, S. M., Homsey, D., Brusch, E., Buyce, C., DeSilva, S., \& Thompson, A. (2013). Prejudice toward American Muslims: An integrated threat analysis. Journal of Intercultural Communication, 32.Retrieved from http://immi.se/intercultural/

Curseu, P. L., Stoop, R., \& Schalk, R. (2007). Prejudice toward immigrant workers among Dutch employees: Integrated theory revisited. European Journal of Psychology, 37, 125-140.

Deetz, S., \& Simpson, J. (2004). Critical organizational dialogue. Open formation and the demand of “otherness". In R. Anderson, L. Baxter, \& K. N. Cissna (Eds.), Dialogue. Theorizing difference in communication studies (pp. 141-158). Thousand Oaks, CA: Sage.

Delcampo, R. G., Haggerty, L. A., \& Haney, M. J. (2011). Managing the multi-generational workforce: From the GI generation to the millennial. Farnham: Ashgate Publishing Group.

ECRI. (2007). Third report on Finland. Retrieved August 11, 2011, from http://hudoc.ecri.coe.int/XMLEcri/ENGLISH/Cycle_03/03_CbC_eng/FIN-CbC-III-2007-23-ENG.pdf Ervasti, H. (2004). Attitudes towards foreign-born settlers: Finland in a comparative perspec tive. In I. S. Teoksessa (Ed.), Yearbook of population research in Finland (pp. 25-44). Helsinki, Finland: Väestöliitto, Väestöntutkimuslaitos.

Finnish National Broadcasting Company (2011). General election results. Retrieved from http://yle.fi.vaalit.tulospalvelu/2011/ 
Ford, R. (2012). Europe's young cosmopolitans: Explaining generational differences in immigration attitudes. University of Manchester, Institute of Social Change working paper.

Ganesh, S., \& Holmes, P. (2011). Positioning intercultural dialogue-theories, pragmatics, and an agenda. Journal of International and Intercultural Communication, 4, 81-86.

González, K. V., Verkuyten, M., Weesie, J., \& Poppe, E. (2008). Prejudice towards Muslims $\quad$ in The Netherlands: Testing integrated threat theory. British Journal of Social Psy chology, 47, 667685.

Helsingin Sanomat. (2011). International edition. Retrieved from http://www.hs.fi/english/article/Estonians + now + Finland $\%$ E2\%80\%99s+largest+immigrant+group $/ 1135264130988$

Jaakkola, M. (2000). Finnish attitudes towards immigrants in 1987-1999. (I. Söderling, Toim.) Helsinki, Finland: Väestöntutkimuslaitos.

Jasinskaja-Lahti, I. (2000). Psychological acculturation and adaptation among Russian speak ing Adolescents in Finland. Retrieved from www.e- thesis:

http://ethesis.helsinki.fi/julkaisut/val/sosps/vk/jasinskaja-lahti/psycholo.pdf Jasinskaja-Lahti, I., \& Liebkind, K. (1998). Content and predictors of the ethnic identity of Russianspeaking immigrant adolescents in Finland. Scandinavian Journal of Psychology, 39, 209-219. Jasinskaja-Lahti, I., \& Liebkind, K. (2001). Perceived discrimination and psychological adjustment among Russian-speaking immigrant adolescents in Finland. International Journal of Psychology, 36, $174-185$.

Jasinskaja-Lahti, I., Liebkind, K., Jaakkola, M., \& Reuter, A. (2006). Perceived discrimina- ～tion, social support networks and psychological well-being among three immigrant groups. Journal of Cross-Cultural Psychology, 37, 293-311. 
Joensu Kaupunki. (2010). Joensuu - Karelian beat and vitality. Retrieved from

http://www.jns.fi/Resource.phx/sivut/sivut-jns/generalinfo/index.htx?lng=en

Kangas, A. (2011). Beyond Russophobia: A practice-based interpretation of Finnish Russian / Soviet relations. Cooperation and Conflict, 46, 40-59.

Karemaa, O. (2004). Foes, fiends, and vermin. Ethnic hatred of Russians in Finland 1917-1923. Retrieved from http://finoved.madistudio.com/?idm=41\&op=main\&idcont=126

Khan, Z., \& Wiseman, R. (2007). What are you going to take from us now? Perceived threats from immigrants, ethnocentrism, and intercultural communication apprehension. Intercultural Communication Studies, XVI: 2, 55-64.

Kim, Y. Y. (1988). Communication and cross-cultural adaptation: An integrative theory. Clevedon, UK: Multilingual Matters.

Kyntäjä, E. (1997). Ethnic remigration from the former Soviet Union to Finland-patterns of ethnic identity and acculturation among the Ingrian Finns. In S. S. Teoksessa (Ed.), Yearbook of population research in Finland (pp. 102-113). Helsinki, Finland: Väestöliitto, Väestöntutkimuslaitos.

Lehtonen, J. (2005). Stereotypes and collective identification. In D. Petkova \& J. Lehtonen (Eds.), Cultural identity in an intercultural context (pp. 67-94). Jyväskylä, Finland: University of Jyvaskyla Press.

Liebkind, K., Mannila, S., Jasinskaja-Lahti, I., Jaakkola, M., Kyntäjä, E., \& Reuter, A. (2004). Venäläinen, virolainen, suomalainen. Kolmen maahanmuuttajaryhmän ko toutuminen Suomeen (Russian, Estonian, Finnish: Integration of Three Immigrant Groups in Finnish Society), Helsinki, Finland: Gaudeamus.

Mannila, S., \& Reuter, A. (2009). Social exclusion risks and their accumulation among Rus sianspeaking, ethnically Finnish and Estonian immigrants to Finland. Journal of Ethnic and Migration Studies, 35, 939-956. 
Näss, H. E. (2010). The ambiguities of intercultural dialogue: Critical perspectives on the European Union's new agenda for culture. Journal of Intercultural Communication, 23. Retrieved from http://immi.se/intercultural.

Niemi, H. (2007). Russian immigrants in Finnish society. Retrieved from http://www.socmag.net/?p=270

Protassova, E. (2008). Teaching Russian as a heritage language in Finland. Heritage Lan guage Journal, 6, 127-152.

Ringo, M. (2005). Communication between Hong Kong and mainland Chinese: Rethinking crosscultural adaptation. International \& Intercultural Communication Annual, 28, 197-213.

Scheibner, G., \& Morrison, T. (2009). Attitudes towards Polish immigrants to the Republic of Ireland: An integrated threat analysis. Ethnic and Racial Studies, 32, 1431-1448.

Schneider, S. L. (2008). Anti-immigrant attitudes in Europe: Outgroup size and perceived ethnic threat. European Sociological Review, 24, 53-67.

Schweitzer, R., Perkoulidis, S. A., Krome, S., Ludlow, C., \& Ryan, M. (2005). Attitudes towards refugees: The dark side of prejudice in Australia. Australian Journal of Psy chology, 57, 170 -179. Stephan, W. G., Diaz-Looving, R., \& Duran, A. (2000). Integrated threat theory and intercul tural attitudes: Mexico and the United States. Journal of Cross-Cultural Psychology, $\quad 31,240-249$. Stephan,W. G., \& Stephan, C.W. (1993). Cognition and affect in stereotyping: Parallel interactive networks. In D. M. Mackie \& D. L. Hamilton (Eds.), Affect, cognition, and stereotyping: Interactive processes in group perception (pp. 111-136). Orlando, FL: Academic Press.

Stephan, W. G., \& Stephan, C. W. (1996). Predicting prejudice. International Journal of Intercultural Relations, 20, 409 - 426. 
Stephan, W. G., Ybarra, O., Martinez, C. M., Schwarzwald, J., \& Turk-Kaspa, M. (1998). Prejudice toward immigrants to Spain and Israel: An integrated threat theory analysis. Journal of Cross-

Cultural Psychology, 29, 559-576. 